\title{
Glacier-like forms on Mars
}

\author{
B. Hubbard, C. Souness, and S. Brough \\ Department of Geography and Earth Sciences, Aberystwyth University, Aberystwyth, UK
}

Correspondence to: B. Hubbard (byh @aber.ac.uk)

Received: 7 May 2014 - Published in The Cryosphere Discuss.: 5 June 2014

Revised: 15 September 2014 - Accepted: 26 September 2014 - Published: 5 November 2014

\begin{abstract}
More than 1300 glacier-like forms (GLFs) are located in Mars' mid-latitudes. These GLFs are predominantly composed of ice-dust mixtures and are visually similar to terrestrial valley glaciers, showing signs of downhill viscous deformation and an expanded former extent. However, several fundamental aspects of their behavior are virtually unknown, including temporal and spatial variations in mass balance, ice motion, landscape erosion and deposition, and hydrology. Here, we investigate the physical glaciology of martian GLFs. We use satellite images of specific examples and case studies to build on existing knowledge relating to (i) GLF current and former extent, exemplified via a GLF located in Phlegra Montes; (ii) indicators of GLF motion, focusing on the presence of surface crevasses on several GLFs; (iii) processes of GLF debris transfer, focusing on mapping and interpreting boulder trains on one GLF located in Protonilus Mensae, the analysis of which suggests a best-estimate mean GLF flow speed of $7.5 \mathrm{~mm} \mathrm{a}^{-1}$; and (iv) GLF hydrology, focusing on supra-GLF gulley networks. On the basis of this information, we summarize the current state of knowledge of the glaciology of martian GLFs and identify future research avenues.
\end{abstract}

\section{Introduction}

Numerous similarities exist between ice-rich landforms on Mars and Earth (e.g., Colaprete and Jakosky, 1998; Marchant and Head, 2003; Forget et al., 2006). Glacier-like forms (GLFs), which comprise one particular subgroup of these features, are strikingly similar in planform appearance to terrestrial valley glaciers (Fig. 1). However, despite this similarity, the fundamental glaciology of martian GLFs remains largely unknown. Improving this knowledge would enhance our understanding both of the specific landforms concerned and of broader planetary issues such as (i) how Mars' present-day landscape was formed, (ii) the presence and phase state of $\mathrm{H}_{2} \mathrm{O}$ on Mars' surface, and (iii) how Mars' climate has changed in geologically recent times. The aim of this paper is to summarize and develop our understanding of the fundamental physical glaciology of Mars' GLFs. As well as summarizing existing knowledge, we provide new observations and interpretations of glacial landforms on Mars and outline potential avenues for future research. However, while a model based on terrestrial analogues, several fundamental controls over martian glaciation contrast sharply with those on Earth. For example, Mars' gravity, at $\sim 3.7 \mathrm{~m} \mathrm{~s}^{-2}$, is less than $40 \%$ of Earth's. Mars' surface temperature varies between $\sim-130$ and $+27^{\circ} \mathrm{C}$, with a mean of $\sim-60^{\circ} \mathrm{C}(\operatorname{Read}$ and Lewis, 2004), $\sim 75^{\circ} \mathrm{C}$ lower than on Earth. Finally, the partial pressure of $\mathrm{H}_{2} \mathrm{O}$ in Mars' near-surface atmosphere is $\sim 1 \mu$ bar, making the planet's surface $\sim 1000$ times drier than Earth's.

Since this paper is intended for readers who are primarily interested in the terrestrial cryosphere, and who may not therefore be familiar with the literature relating to the martian cryosphere, a list of the acronyms used herein is given in Table 1.

\subsection{Background}

\subsubsection{GLF classification, location and form}

Mars' mid-latitude regions, between $\sim 20$ and $\sim 60^{\circ} \mathrm{N}$ and $\mathrm{S}$, host numerous landforms and surface deposits that bear a striking resemblance to small-scale terrestrial ice masses (e.g., Souness et al., 2012). These landforms, being composed predominantly of $\mathrm{H}_{2} \mathrm{O}$ ice (Holt et al., 2008; Plaut et al., 2009) and exhibiting surface morphologies consistent with viscous flow (Marchant and Head, 2003; Head et al., 2010), have come to be known collectively as viscous 


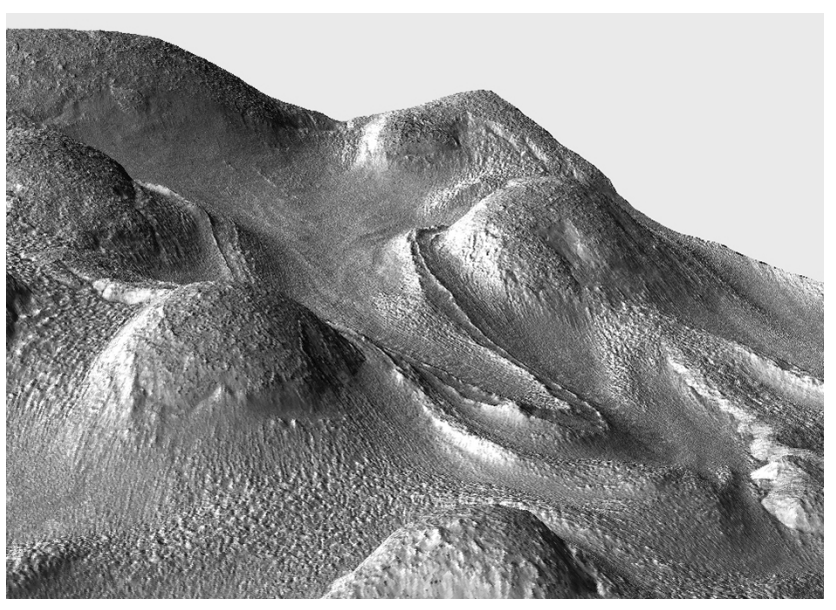

Figure 1. A 3-D image of a typical martian GLF (\#948 in the inventory of Souness et al., 2012), which is $\sim 4 \mathrm{~km}$ long and $\sim 600 \mathrm{~m}$ in altitudinal range. The GLF shows evidence, through deformed chevron-like surface ridges, of down-slope flow; is longer than it is wide; and is bounded on all sides. This well-studied GLF is also bounded by a series of well-defined moraine-like ridges. Image reproduced after Hubbard et al. (2011).

Table 1. List of commonly used terms and corresponding acronym.

\begin{tabular}{ll}
\hline Term & Acronym \\
\hline Glacier-like form & GLF \\
Viscous flow feature & VFF \\
Lobate debris apron & LDA \\
Lineated valley fill & LVF \\
Moraine-like ridge & MLR \\
Mars Reconnaissance Orbiter & MRO \\
Context (Camera) & CTX \\
High Resolution Imaging Science & HiRISE \\
Experiment (camera) & \\
Shallow Subsurface Radar & SHARAD \\
\hline
\end{tabular}

flow features, or VFFs (Milliken et al., 2003; Souness and Hubbard, 2012). Glacier-like forms, or GLFs, are a distinctive subtype of VFF that are elongate and similar in appearance and overall morphology to terrestrial valley glaciers. GLFs thereby generally form in small cirque-like alcoves or valleys, appear to flow downslope between bounding sidewalls, and terminate in a distinctive tongue which may or may not feed into a higher-order ice-rich terrain type. GLFs thereby represent the lowest-order component of what Head et al. (2010) referred to as Mars' integrated glacial landsystem. According to this model, GLFs flow and may merge downslope to form broad, rampart-like lobate debris aprons (LDAs) (Squyres, 1978, 1979). LDAs may, in turn, coalesce, typically from opposing valley walls, to form lineated valley fills (LVFs), which take the form of complex and contorted surfaces that often exhibit no obvious flow direction.

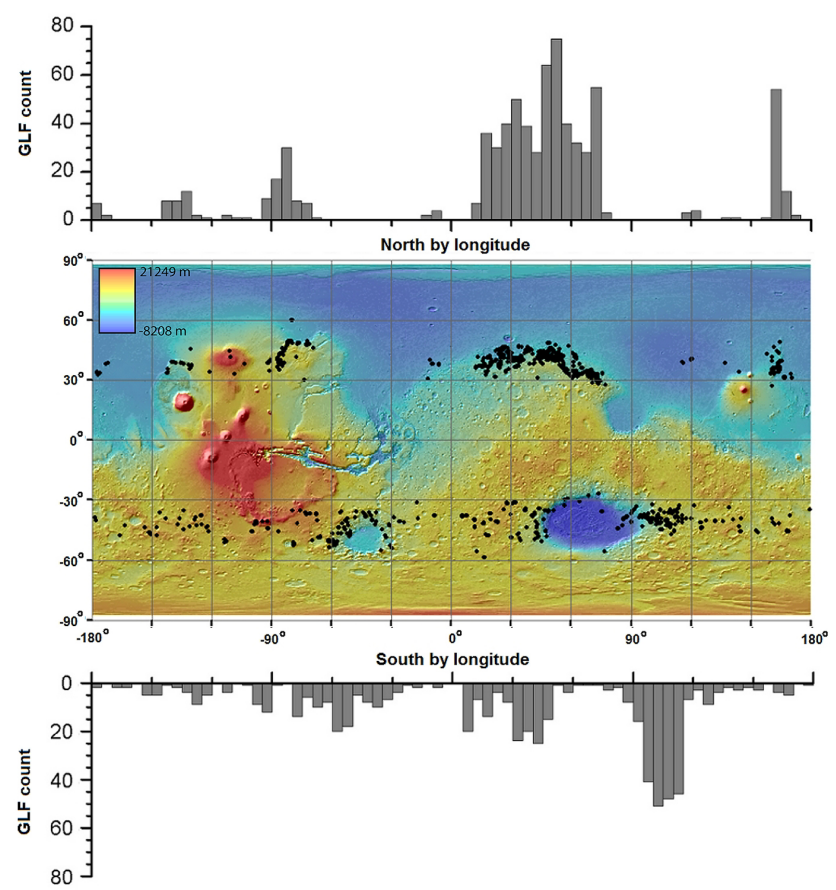

Figure 2. The spatial distribution of Mars' 1309 GLFs as identified by Souness et al. (2012).

In their inventory of Mars' GLFs, Souness et al. (2012) inspected $>8000$ Context Camera (CTX) images, covering $\sim 25 \%$ of the Martian surface, and identified 1309 individual forms, reporting the location (Fig. 2) and basic morphometry of each. Hereafter, we refer to specific GLFs through their classification number in this inventory, available as a supplement accompanying Souness et al. (2012). Of the total population, 727 GLFs $(56 \%)$ were found in the northern hemisphere and $582(44 \%)$ in the southern hemisphere, with GLFs showing a preference for the mid-latitudes (centered on a mean latitude of $39.3^{\circ}$ in the north and $-40.7^{\circ}$ in the south). Although Souness et al. (2012) did not normalize their GLF count to (spatially variable) image coverage, inspection of Fig. 2 strongly suggests that GLFs are locally clustered in both hemispheres, for example along the so-called "fretted terrains" (Sharp, 1973) of Deuteronilus Mensae, Protonilus Mensae and Nili Fossae in the north and around the Hellas Planitia impact crater in the south (Fig. 2). GLF morphometry was found to be remarkably similar between the two hemispheres, with a mean GLF length of $4.91 \mathrm{~km}$ in the north and $4.35 \mathrm{~km}$ in the south, and a mean GLF width of $1.26 \mathrm{~km}$ in the north and $1.34 \mathrm{~km}$ in the south. Similar to on Earth, a pronounced preference for a poleward orientation was also found, with GLFs having a mean bearing of $26.6^{\circ}$ (NNE) in the northern hemisphere and $173.1^{\circ}$ (SSE) in the southern hemisphere - indicating a strong sensitivity to insolation. These interhemispheric similarities in distribution and morphometry indicate that all martian GLFs 
share a high degree of commonality in terms of composition and formation. These are considered below.

\subsubsection{GLF composition}

The precise composition of GLFs is still unknown due to the fact that they are almost ubiquitously covered in a layer of fine-grained regolith. Debate surrounding the amount of water ice involved in VFF composition (including GLFs) has led to varying interpretations being advanced, including ice-assisted talus flows $(\sim 20-30 \%$ ice; Squyres, 1978, 1979), rock glaciers ( 30-80\% ice; Colaprete and Jakosky, 1998; Mangold, 2003), and debris-covered glaciers (> $80 \%$ ice; Head et al., 2005; Li et al., 2005). Since the distinctions between these forms, and between them and "standard" glaciers, is not sharply defined even on Earth, we are not yet in a position to definitively attribute martian equivalents to any or all of them. We therefore follow the convention of much of the published literature and refer to these forms as "glacier-like", accepting that they may eventually, when more information becomes available, be more accurately reclassified as some related form such as rock glaciers or mass flows. That said, the latter is unlikely to hold universally on Mars since many GLFs do not show distinctive source areas for their mass, many have lost substantial mass since their formation (Sect. 2.2 below), and many appear from radar data to be composed largely of water ice (below). Hubbard et al. (2011) noted that boulder incisions into the unconsolidated surface of GLF \#948 located in the north wall of Crater Greg, eastern Hellas, were some decimeters deep, representing a minimum surface dust thickness at this location. There have been very few direct observations of the interior of GLFs, but Dundas and Byrne (2010) reported the capture of very recent meteorite strikes that indicated the presence of relatively clean (i.e., debris poor) massive ice at a depth of some centimetres to metres below the surface. Furthermore, data from the shallow subsurface radar (SHARAD) sensor, mounted on the Mars Reconnaissance Orbiter (MRO), suggest that many VFFs (including GLFs) may well be composed of massive $\mathrm{H}_{2} \mathrm{O}$ ice with minimal lithic content (Holt et al., 2008; Plaut et al., 2009). These findings led to the widespread acceptance that $\mathrm{H}_{2} \mathrm{O}$ ice accounts for the dominant portion of GLF mass. However, the presence of a lithic component has been demonstrated by ice fade through sublimation following recent impact exposures (Dundas and Byrne, 2010), and the precise proportions of ice-rock mixture, particularly at depth, are still unknown.

\subsubsection{GLF formation}

A continuing point of discussion relates to precisely how and when GLFs formed. It is generally agreed that GLFs are now largely relict forms dating to a past, but relatively recent, martian ice age (see Kargel, 2004). While it is thought that Mars' last major ice age ceased when the planet's obliquity changed from $\sim 35$ to $\sim 25^{\circ}$ between 4 and 6 million years ago (Laskar et al., 2004), evidence of a subsequent, Late Amazonian ice age has been proposed (e.g., Head et al., 2003). It is thought that obliquity still exceeded $30^{\circ}$ during periods of short-term obliquity cycles $(\sim 100 \mathrm{ka})$ between $\sim 2$ and $\sim 0.5 \mathrm{Ma}$ BP. During these intermittent periods, increased solar radiation led to the melting of Mars' polar caps, the release of moisture into the atmosphere, and its precipitation as snow or condensation above or within the ground at lower latitudes (e.g., Forget et al., 2006; Hudson et al., 2009; Schon et al., 2009). This ice deposition extends well into Mars' mid-latitudes, where it appears to have survived, preserved beneath surface regolith, until the present day. Still, the mechanisms by which GLFs first accumulated sufficient ice-rich mass to flow downslope and acquire their distinctive surface morphologies remain uncertain.

\section{The glaciological characteristics of martian GLFs}

\subsection{Approach and methods}

Each of the following sections both summarizes published information and supplements that information with new data from the analysis of images acquired by MRO's CTX, at a resolution of $\sim 6 \mathrm{~m}$ per pixel, or High Resolution Imaging Science Experiment (HiRISE) camera, at a resolution of $\sim 0.3 \mathrm{~m}$ per pixel. Maps were constructed from these images using ArcMap GIS software and interpretations additionally drew on elevation data produced by the Mars Orbiter Laser Altimeter (MOLA), at a typical resolution of 128 pixels per degree, mounted on the Mars Global Surveyor spacecraft.

\subsection{GLF extent}

Recent observations suggest that current GLFs are the remnants of a once far larger ice mass (e.g., Dickson et al., 2010; Sinha and Murty, 2013) that was most extensive during a hypothesized last martian glacial maximum, or LMGM (Souness and Hubbard, 2013). Such an expanded former extent has been inferred from detailed regional geomorphological reconstructions, for example identifying former ice limits from variations in surface texture and the existence of distal moraine-like ridges. Allied to local topography, such mapping has allowed the reconstruction of both former ice extent and local ice-flow directions (e.g., Dickson et al., 2008). However, debate persists concerning both the precise timing of the LMGM and the extent and volume of ice coverage at the time. The complexity of this issue is compounded by the timescales involved, with best estimates currently placing the LMGM at 5-6 Ma BP, but possibly continuing closer to the present day (Touma and Wisdom, 1993; Head et al., 2003) (Sect. 1.1.3 above).

The outlines of many GLFs are clearly demarcated by the presence along their margins and front of bounding morainelike ridges, or MLRs (Arfstrom and Hartmann, 2005). These 


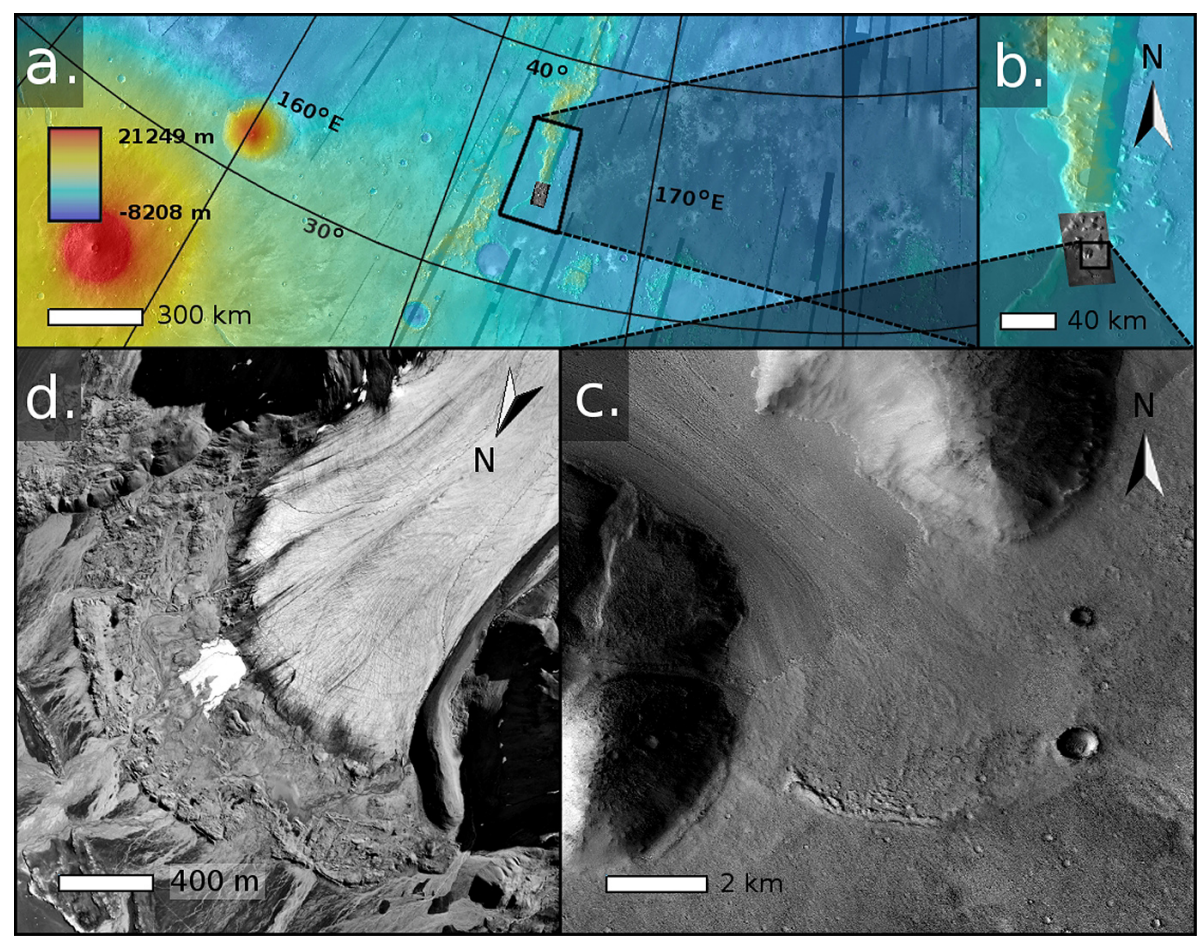

Figure 3. Case study illustrations of the former extent of martian GLF \#146 showing background MOLA elevation images (a and b), and a CTX image expansion (c). The forefield of terrestrial Midre Lovénbreen, Svalbard, is shown for comparison (d).

landforms are commonly raised above the present GLF surface and are texturally distinct from their surroundings. One particular Amazonian-aged ( $10 \mathrm{MaBP})$ GLF located in Crater Greg, eastern Hellas $\left(-38.15^{\circ} \mathrm{N}, 246.84^{\circ} \mathrm{E}\right)(\# 948)$, has been the focus of much study (e.g., Hartmann et al., 2003, 2014; Kargel, 2004; Hubbard et al., 2011). In an analysis of this particular GLF, Hubbard et al. (2011) described a sequence of up to four distinct raised bounding ridges located along the GLF's margins. The authors also described two surface terrain types in the GLF's lower tongue, "linear terrain" and "mound and tail terrain", as being possible exposed subglacial bedforms. Overall, this led these authors to suggest that the GLF's moraine-bounded outline presently represents a glacial basin in which the lower zone now comprises an exposed former glacier bed, while the basin's upper zone still hosts a degraded ice mass. In this case, therefore, the present-day GLF outline incorporates both an ice mass and its immediate proglacial area. This particular GLF's multiple bounding moraines were also interpreted in terms of a general recession punctuated by several (at least three) episodes of minor readvance or stillstand.

At a larger scale, GLFs form the first order of the Martian glacial landsystem (Head et al., 2010) (Sect. 1.1 above), which is present throughout substantial parts of the planet's northern and southern mid-latitudes (Milliken et al., 2003; Souness and Hubbard, 2012). Many of the ice masses forming this landsystem are thought to have been substantially more advanced and thicker in the past, carrying important implications for reconstructions of climatic variability on Mars. For example, Dickson et al. (2008) reconstructed former glacial limits in the Protonilus Mensae region $\left(54.55^{\circ} \mathrm{E}\right.$, $40.80^{\circ} \mathrm{N}$ ) based on the identification and mapping of former glacial highstands. The analysis indicated a maximum ice thickness of $>2 \mathrm{~km}$ at LMGM and a downwasting of at least $920 \mathrm{~m}$ since then. Although reconstructed flow directions were questioned in detail by Souness and Hubbard (2013), this analysis indicates substantially thicker ice in the geologically recent martian past.

Several studies have also pointed out that GLFs appear to be distinctive from the underlying ice-rich (LDA or LVF) material onto which they appear to have flowed (e.g., Levy et al., 2007; Baker et al., 2010; Sinha and Murty, 2013). This material contrast has been interpreted as signifying the possibility of a marked age difference between the two surfaces, suggesting two or more glacial events with at least one smallscale or "local" glacial phase advancing over an earlier "regional" glaciation (e.g., Head et al., 2003; Levy et al., 2007; Dickson et al., 2008; Sinha and Murty, 2013).

Glacial activity has also been identified outside the midlatitude regions. As well as the well-studied polar ice caps (e.g., Seu et al., 2007; Phillips et al., 2008), degraded glacierlike features have been described surrounding the shield volcano of Arsia Mons $\left(-0.31^{\circ} \mathrm{N}, 239.00^{\circ} \mathrm{E}\right.$ ) (Head and Marchant, 2003) and in high-latitude $\left(70.32^{\circ} \mathrm{N}, 266.45^{\circ} \mathrm{E}\right)$ craters (Garvin et al., 2006). The identification of features and landforms of glacial origin across vast areas of Mars' 
present surface has also led to suggestions that continental glaciation may once have occurred on Mars (Kargel and Strom, 1992; Kargel et al., 1995; Fastook et al., 2014; Hobley et al., 2014).

\section{Case study: reconstructing former GLF extent}

GLF \#146 is $\sim 12 \mathrm{~km}$ long, $\sim 5 \mathrm{~km}$ wide and located in the Phlegra Montes region of Mars' northern hemisphere $\left(164.48^{\circ} \mathrm{E}, 34.13^{\circ} \mathrm{N}\right.$ ) (Fig. 3). This region is largely formed from several massifs that stretch from the northeastern section of the Elysium Volcanic Province to the dichotomy lowlands. GLF \#146 is located on the southern tip of a massif range and converges from a wide upper basin between two rock outcrops into an elongate lower tongue. The main tongue of this GLF shows distinctive surface lineations and textures that indicate the presence of three separate major flow units. Several arcuate, linear raised features or MLRs are located in the foreground of the current GLF. This particular case is of interest because these MLRs are located some distance from the GLF's current margin, indicating formation at some time in the past when the GLF was at a more advanced position than at present.

The geomorphological interpretation of GLF \#146 (Fig. 4), reconstructed from CTX images alone, reveals that the region in front of the current GLF is characterized by two distinctive terrain types. At the broadest scale, both terrains are clearly part of the ice-rich, fretted terrain found throughout Mars' mid-latitudes but particularly characteristic of Deuteronilus Mensae, Protonilus Mensae and Nili Fossae (Sharp, 1973). However, both terrains also differ in several important details, indicating distinctive mechanisms of formation and/or subsequent history. The first terrain type, "arcuate terrain", forms a $\sim 3.3 \mathrm{~km}$ wide band around the GLF's current margin. This terrain is characterized by arcuate ridges whose shadows indicate that they are raised above the adjacent ground, forming distinct local topographic highs $\sim 0.1-1.7 \mathrm{~km}$ long and $5-10 \mathrm{~m}$ wide. These ridges show distinct similarities in morphology and spatial relationships to MLRs identified elsewhere on Mars (Arfstrom and Hartmann, 2005), which are the martian equivalent of terminal moraines on Earth (e.g., Fig. 3d). The arcuate ridges forming this terrain increase in size and coherence away from the GLF's margin (Fig. 3c) such that they are almost unbroken along the terrain's full distal edge. The ridges are smaller and more fragmented nearer to the GLF's margin. The second terrain type, "smooth terrain", extends beyond the arcuate terrain for tens of hundreds of kilometres into the forefield's lower plains. This terrain appears at the broadest scale to be visually smooth with few undulations relative to the arcuate terrain. Close inspection also indicates irregular mottling and a greater concentration of impact craters on the smooth terrain than on either the arcuate terrain or the GLF proper (Fig. 4).
The location and characteristics of the two proglacial terrain types outlined above provide some basis for their interpretation. We infer that the arcuate area directly in front of the GLF represents the geologically recent former extent of the GLF. Like on Earth, the MLRs represent the former locations of the GLF's terminus, with the outermost MLR representing the maximum former extent of the GLF and each subsequent ridge representing a former terminal position (of minor advance or slowdown) during a period of general GLF recession. The sequence of multiple terminal MLRs thereby implies that the GLF has undergone a cyclic or punctuated recession. The lower density of craters on the GLF and its encompassing arcuate terrain relative to the outer smooth terrain is consistent with the younger age for the deposition or exposure of the former. Indeed, the general lack of resolvable craters on the arcuate terrain and on the GLF itself, although insufficient in number to analyze formally, suggests that the feature is of a geologically very young age. On a regional scale, other degraded ice-related features have been reported in the northwestern region of Phlegra Montes (Dickson et al., 2010), suggesting that regional glaciation may have occurred at Phlegra Montes in the recent past and that we currently see their diminished remains.

Overall, we interpret the GLF located in Phlegra Montes as an ice-rich mass that was once much larger than its current extent, with the outer MLR marking its former maximum extent. The continuity of the smooth plains to the east, combined with a lack of further evidence of ice-related processes, suggests that the GLF reported here marks the outer limit of glacial activity of the Phlegra Montes region. It appears that the GLF coalesced from a wide upper basin into a narrow tongue before spreading out onto the flatter plains, much like a piedmont glacier on Earth. Subsequently the GLF's terminus has retreated $\sim 3.3 \mathrm{~km}$ to its current position, apparently through periods of cyclic or punctuated standstill, particularly early on during the period of general recession. Similar evidence for GLFs representing degraded landforms has been presented elsewhere in Mars' mid-latitudes (e.g., Hubbard et al., 2011; Souness and Hubbard, 2013), indicating it is possible that GLFs were once a much larger feature on Mars' surface. Further, the appearance of deposits indicating the GLFs former extent would also imply that GLFs have been active and dynamic in the past.

\subsection{GLF motion}

While no data have yet been obtained that reveal either rates or mechanisms of GLF movement (cf. Sect. 2.4.1 below), such motion has been both modelled and inferred from their overall lobate shape and the presence of flow structures on their surface. These flow structures are typically shaped like chevrons (e.g., Fig. 1) consistent with a transverse surface velocity profile similar to that measured at terrestrial glaciers, i.e., increasing inwards from the glacier's lateral margins towards the centerline, where velocity is highest above the 


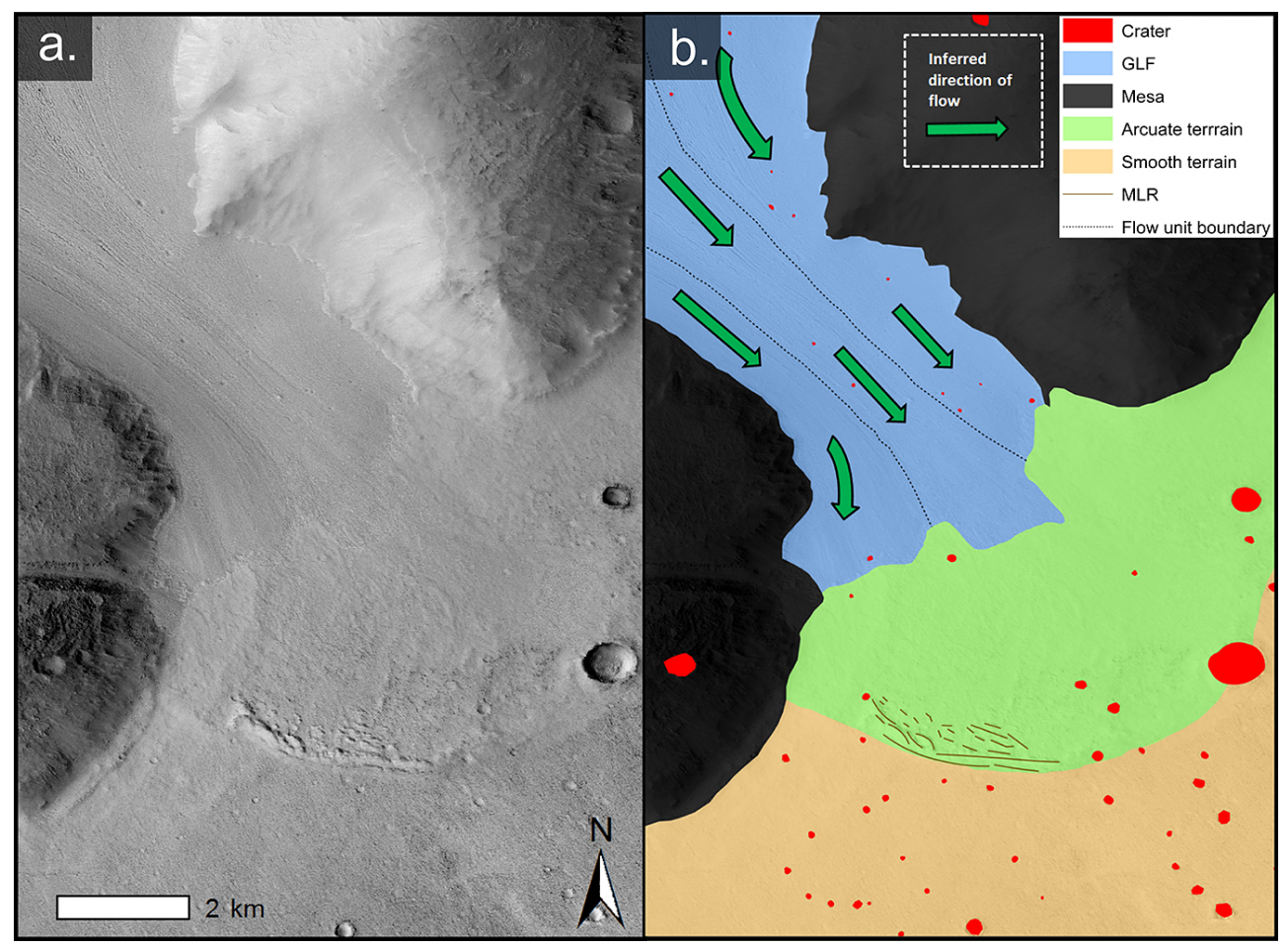

Figure 4. Geomorphological interpretation of GLF \#146 illustrated in Fig. 3c.

thickest ice. There is therefore little doubt that GLFs have moved, at least through viscous deformation. However, there is no evidence that mass is continuing to accumulate on present-day GLFs, nor that they are still moving. In an effort to shed some light on the likelihood of GLF motion, Milliken et al. (2003) applied the multi-component constitutive relation of Goldsby and Kohlstedt (2001) to typical ranges of VFF temperature, slope and (assumed) ice grain size. For an assumed $10 \mathrm{~m}$ thick VFF deposit, Milliken et al. (2003) estimated shear stresses of $10^{-1.5}-10^{-2.5} \mathrm{MPa}$ and consequent strain rates on the order of $10^{-11}-10^{-16} \mathrm{~s}^{-1}$. Based on these rates, the authors estimated it would take between $3 \mathrm{ka}$ and $300 \mathrm{Ma}$, respectively, to produce a shear strain of $100 \%$, which was in agreement with age estimates of the VFF $\left(10^{5}-\right.$ $10^{7}$ a). Although the application of this stress-strain relationship to martian VFF conditions represented a major advance, the model was not distributed spatially and was not therefore applied to, nor considered, any particular VFF geometry. Moreover, the possible presence of liquid water within or below VFFs was (and still is) also unknown. All VFF motion was therefore assumed to occur through deformation of a spatially homogeneous ice-dust mixture.

\subsubsection{Crevassing as an indicator of GLF motion}

Fracturing is a universal diagnostic indicator of high tensile or shear strain rates within terrestrial ice masses. Further, the orientation of individual crevasses and the size and shape of crevasse fields reflect the strain rate, and strain history, of specific parcels of ice (e.g., Herzfeld and Clarke, 2001). Crevasses have been reported on a variety of icerich surfaces on Mars. For example, fractures observed on the floor of certain craters in Xanthe Terra formed part of what Sato et al. (2010) described as "chaotic" terrain. Pierce and Crown (2003) also reported transverse cracks in debris apron deposits in eastern Hellas, and interpreted them specifically as brittle extensional crevasses. Fractures have also been observed at the edge of high $(>800 \mathrm{~m})$ icy scarps on Mars' north and south polar ice caps (Byrne et al., 2013). These fractures appear to act as planes of weakness for occasional collapse events that have been observed in repeat satellite images (Russell et al., 2008). Kargel (2004) made specific reference to the presence of crevassing on martian GLFs, where the varying size, morphology and overall state of preservation of crevasses were interpreted in terms of formation over a considerable period of time, possibly continuing to the present day. This indicates that Mars' GLFs do appear to be, at least in some cases, still actively flowing.

Below, we present an analysis, based on new data, of the extent and nature of crevasses visible on the surface of martian GLFs.

\subsubsection{Concentration and location of crevassed GLFs}

From an overall population of $\sim 1300$ GLFs (Souness et al., 2012), surface crevasses are present on 64 individual forms 

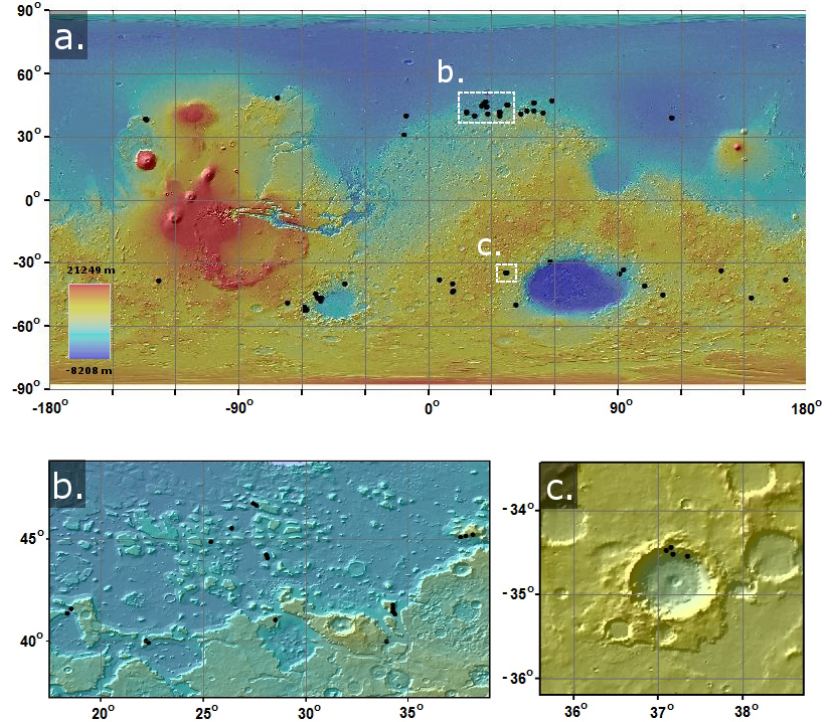

Figure 5. The distribution of crevassed GLFs on Mars (a), with expansions of GLF clusters in Deuteronilus Mensae (b) and western Hellas Planitia (c).

( $\sim 5 \%$ of the total population). Of these crevassed GLFs, $37(57.8 \%)$ are located in the northern hemisphere and 27 $(42.2 \%)$ in the southern hemisphere (Fig. 5a). While this interhemispheric division mirrors that of the overall GLF population of $55.5 \%$ on the northern hemisphere and $44.5 \%$ in the southern hemisphere (Fig. 2), crevassed GLFs are preferentially clustered in certain regions relative to their parent GLFs populations. These clusters are particularly notable in northwestern Argyre in the southern hemisphere and in Deuteronilus Mensae and Protonilus Mensae in the northern hemisphere (Fig. 5). Crevassing therefore occurs, or is at least more readily visible (i.e., exposed by the absence or excavation of supraglacial regolith), in these specific areas.

\subsubsection{Examples of GLF crevasse morphologies and their interpretation}

Crevassing occurs where tensile strain rate of ice exceeds a critical threshold (Vaughan, 1993). Such high strain rates can result from several factors including local changes in mass balance, ice surface and/or bed slope, ice thickness, and basal traction. Similar to crevassed ice masses on Earth, many of the crevasse fields identified on martian GLFs fall into one of a small number of repeated patterns, illustrated below through examples of four sets of crevasses from two martian GLFs.

Example crevasse set \#1 (ECS1) (Fig. 6) is on GLF \#1054, located to the east of the large Hellas Planitia impact crater in Mars' southern hemisphere $\left(102.65^{\circ} \mathrm{E},-40.85^{\circ} \mathrm{N}\right)$. This particular GLF exhibits two crevasse sets. ECS1 (Fig. 6c), comprises a dense cluster of transverse linear crevasses, typically $100-250 \mathrm{~m}$ long and up to $50 \mathrm{~m}$ wide, that coincide with an abrupt increase in slope, just down-flow of the point at which the GLF flows out of a cirque-like alcove. The location and transverse orientation of ECS1 conforms to longitudinal extension associated with the acceleration of GLF \#1054 as it flows over its cirque lip and moves down a steeper slope. The physical setting, strain regime and pattern of these crevasses are similar to icefalls, which are commonplace on terrestrial valley glaciers.

ECS2 (Fig. 6d) is also located on GLF \#1054, but in its upper reaches. This set of linear crevasses forms a discontinuous band aligned adjacent and parallel to the GLF's headwall contact, similar to glacier bergschrunds in Earth. On Earth, bergschrunds indicate gravity-driven ice flow away from the headwall of a glacier where the ice surface slope is locally sufficiently steep to induce brittle fracture (Mair and Kuhn, 1994).

ECS3 (Fig. 7) is on GLF \#541, located in Deuteronilus Mensae in Mars' northern hemisphere $\left(38.18^{\circ} \mathrm{E}, 45.14^{\circ} \mathrm{N}\right)$. This crevasse field is located along the GLF's western flank (Fig. 7b) and consists of multiple, highly degraded fractures that extend towards the GLF's centerline from its lateral margin. These crevasses are aligned slightly up-valley, and progressively rotate towards a more transverse alignment towards the GLF's terminus. On Earth, such a crevasse pattern indicates the presence of extensional lateral shear within a glacier, caused by friction between the ice and the valley walls. Once formed, the crevasses rotate in accordance with a general increase in longitudinal ice velocity away from the valley sides and towards a glacier's centerline. The similar morphology of the crevasses observed on GLF \#541 (Fig. 7b) and the lateral crevasses on terrestrial glaciers indicate that martian GLFs are, or have been, characterized by a similar geometry and velocity field to terrestrial valley glaciers. This particular case provides evidence that GLFs both thicken towards their centerline (where on Earth such valleys are typically parabolic in cross section; Harbor, 1995) and that the associated increase in ice thickness causes a corresponding increase in ice velocity.

ECS4 (Fig. 7c) is located near the terminus of GLF \#541. This crevasse field comprises longitudinally orientated crevasses that are located along the approximate centerline of the GLF and diverge laterally as the terminus of the glacier spreads to form a piedmont lobe (Fig. 7c). A series of major ridges is also seen in this zone, located just up-flow of an apparent bedrock protuberance. These ridges are aligned orthogonal to the GLF's flow direction and to ECS4. The crevasses forming ECS4 are virtually identical in context and shape to longitudinal crevasses on Earth's glaciers, formed by transverse extension. In this case, we interpret ECS4 as forming through a combination of transverse extension, associated with the spreading of the piedmont lobe, and longitudinal compression as the terminus of the GLF abuts the bedrock protuberance. This interpretation is consistent with the transverse ridges in front of GLF \#541, which are similar to compressional ridges, or push moraines, commonly found 


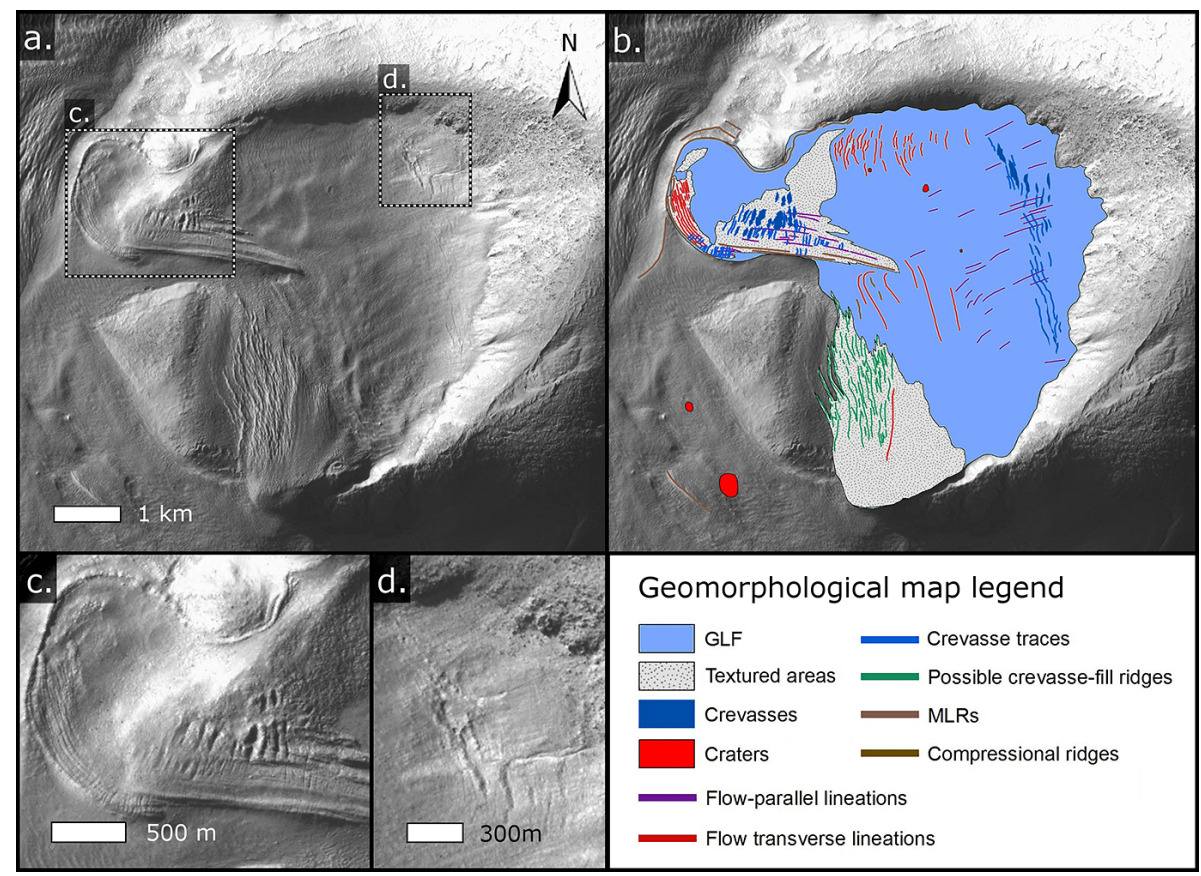

Figure 6. CTX image of crevassed GLF \#1054, located in eastern Hellas (Fig. 5a) (a), along with its geomorphological interpretation (b) and expansions of two crevasse sets (c and $\mathbf{d})$.

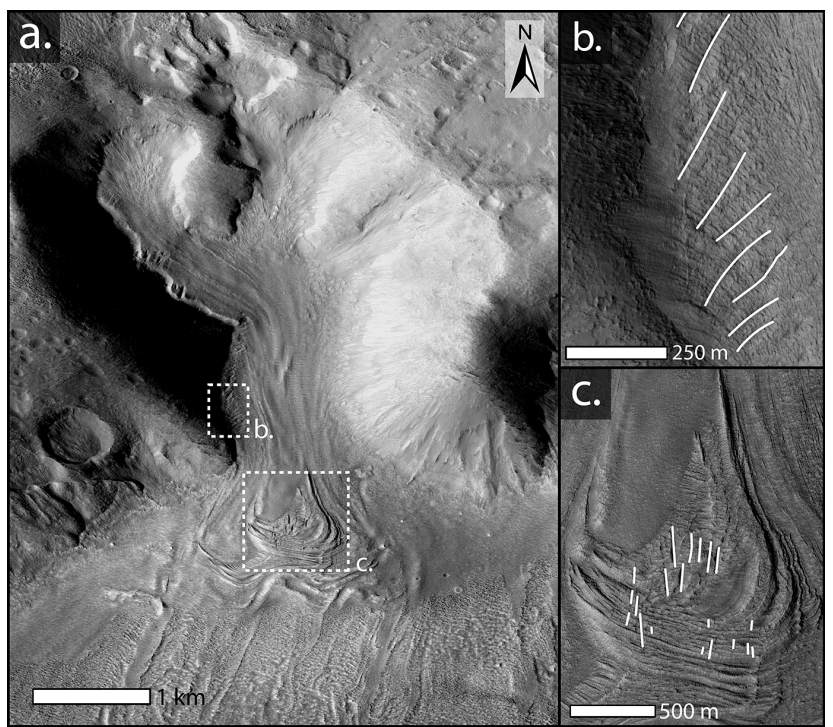

Figure 7. CTX image of crevassed GLF \#541, located in Deuteronilus Mensae (Fig. 5b) (a), along with expansions of two crevasse sets (b and $\mathbf{c}$ ).

in the proglacial areas of valley glaciers on Earth. It is also apparent from Fig. 7 that the edges of the crevasses forming ECS4 are particularly sharply defined, suggesting that they are young and have been subjected to minimal degradation relative to other examples (e.g., ECS2; Fig. 6d).
The presence of crevasses on martian GLFs indicates that their deformation can be achieved through brittle fracture as well as ductile flow. The interpretations of such crevasse fields presented above indicates that high GLF strain rates can be caused by several factors that are similar to terrestrial ice masses, including (i) variable bed slope, (ii) lateral drag at shear margins (e.g., along valley sides), and (iii) spatial variations in traction at the ice-bed interface. These case studies also suggest that GLFs share certain geometrical and dynamic characteristics with Earth's glaciers, such as a parabolic cross section and its associated transverse velocity profile, characterized by faster motion along the centerline than along the margins. These observations also show that crevasses on Mars' GLFs range from highly degraded to sharp-edged, suggesting that crevasses have been formed over a considerable length of time, possibly continuing to the present day.

\subsection{GLF debris transfer and deposition}

The presence of moraine-like ridges (MLRs) on Mars' GLFs (Sect. 2.2 above) implies the entrainment, transport and deposition of substantial volumes of debris. While very little research has been directed specifically at evaluating how and to what extent GLFs (or VFFs more broadly) have shaped Mars' landscape, some relevant information is available. For example, lithic debris can be supplied to the uppermost reaches of GLFs from steep bounding headwalls that appear to be composed of weathered bedrock and unstable 
boulder-rich deposits (Hubbard et al., 2011). These authors likened this "incised headwall terrain" to ice-marginal lateral moraines on valley glaciers on Earth. The base of this headwall was composed of a strip of boulder-rich deposits, some tens of metres wide, into which closely spaced parallel incisions had been cut, similar in appearance to water-related erosional gullies on Earth. Below this incised headwall terrain, several boulders appeared to have rolled downslope and come to rest on the surface of the GLF (their Fig. 7b). Such headwalls thereby supply both coarse-scale rockfall and, if the headwall gullies are eroded fluvially, fine-scale washed debris to the GLF surface.

Many GLFs also appear to host medial moraines, present as raised linear deposits, typically metres to tens of metres wide and up to some kilometres long, which are aligned parallel to the direction of flow. Moreover, these lineations occasionally correspond to the common edge of two adjoining adjacent source flow units such as a tributary flow unit joining a glacier's trunk or flow re-converging after splitting around a bedrock protrusion or nunatak. Both situations closely correspond to the most common mechanism of medial moraine formation on Earth, as coalesced lateral moraines.

\section{Case study: supra-GLF boulder trains}

Substantial coarse debris appears to be present on the surface of GLF \#498 (Fig. 8), located on the inner edge of the southern rim of Moreaux Crater in Protonilus Mensae $\left(44.06^{\circ} \mathrm{E}, 40.82^{\circ} \mathrm{N}\right)$. GLF \#498 is $\sim 2 \mathrm{~km}$ wide and $\sim 12 \mathrm{~km}$ long from terminus to confluence where two major source areas converge into a single north-flowing trunk. Surface landforms and textures indicate the presence of numerous smaller source areas along the GLF's flanks. This GLF is unusual and interesting because it exhibits extensive surface boulder deposits that are not confined to the GLF's margins but are located throughout the GLF, extending right to its centre. Geomorphological mapping of GLF \#498 (Fig. 9) reveals that its supra-GLF debris is largely formed of bouldersized material that protrudes conspicuously above the host terrain, making them clearly visible on the high-resolution HiRISE images used to map the feature. Indeed, hundreds of individual boulders, which are commonly $1-5 \mathrm{~m}$ across, can readily be identified in the images. Much of this debris appears to belong to one of nine clusters or populations, labeled A-I in Fig. 9. Populations A, B and C represent 1-2 km long, elongate boulder trains located in a medial supra-GLF position as one major tributary enters the principal tongue from the west. All three populations are conformable with surface lineations and raised textured areas as they together bend northwards as they join the GLF's main channel. Approximately $3 \mathrm{~km}$ down-flow of population $\mathrm{C}$, population $\mathrm{G}$ is notably elongate, extending for more than $2 \mathrm{~km}$ along the GLF but attaining a width of no more than $\sim 20 \mathrm{~m}$. This boulder train rests on the west-facing flank of a raised supraGLF MLR and appears as a continuation of population C. In

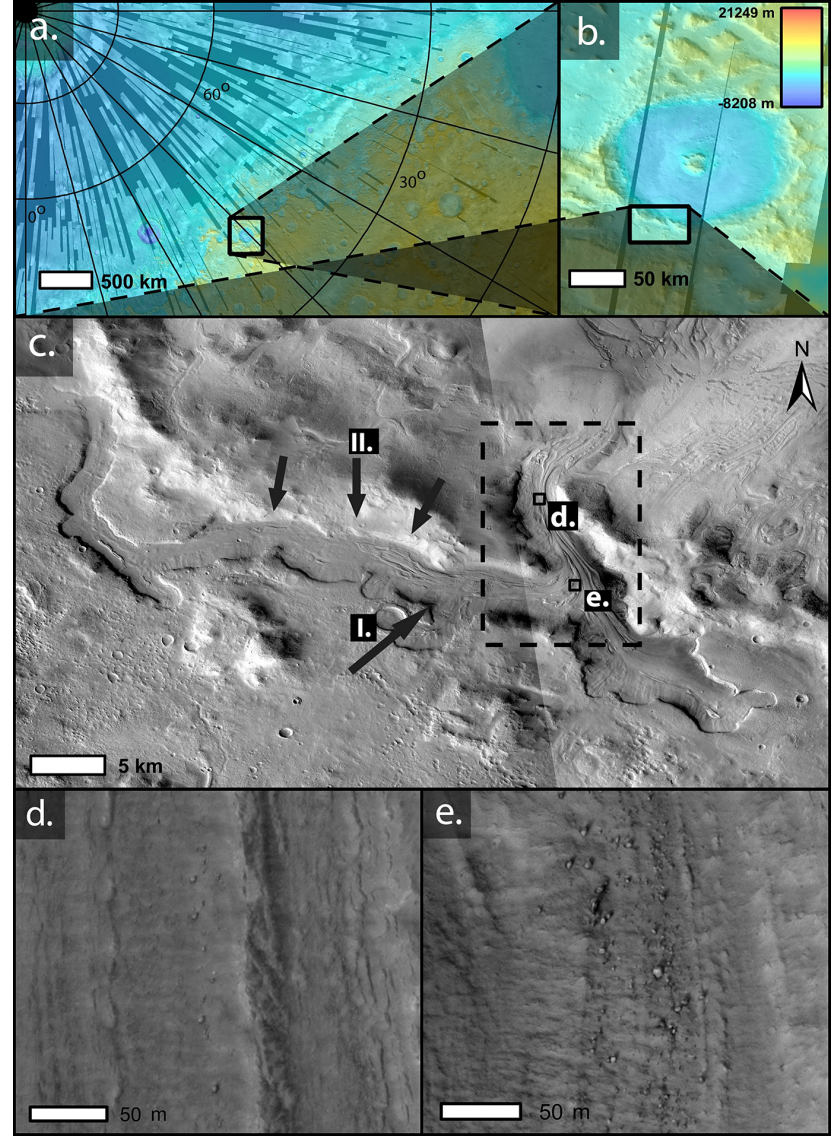

Figure 8. HiRISE image of GLF \#498, located in Protonilus Mensae showing background MOLA elevation images (a and b), and an expansion of GLF \#498 (c), along with two examples of surface boulder exposures (d and e). Arrows I. and II. on panel (c) indicate likely source areas for supra-GLF boulders illustrated in Fig. 9 and discussed in the text. The dashed box is expanded in Fig. 9.

contrast, populations $\mathrm{D}$ and $\mathrm{H}$ to the east and $\mathrm{E}, \mathrm{F}$ and $\mathrm{I}$ to the west all appear to extend over $\sim 50-100 \mathrm{~m}$ away from steep and rocky valley-side walls.

It is apparent from Fig. 9 that boulders have been supplied to several locations on the surface of GLF \#498 and that they have subsequently moved across the GLF. Some of this movement may have been by active rolling, particularly away from immediate valley-side supply areas and towards the GLF's centreline, such as in the cases of populations D, E, F, H and I. However, some or all of these populations may also have experienced passive redistribution, with boulders being advected with GLF motion. Without knowledge of the precise source area and maximum reach of individual boulders, it is not possible to determine the component of passive advection in these cases, but it could have been anything up to the maximum dimension of these populations, $\sim 2 \mathrm{~km}$. In contrast, there appears to be no local source area for the boulders forming trains A, B, C and G; the boulders comprising these elongate trains are almost certainly sourced 


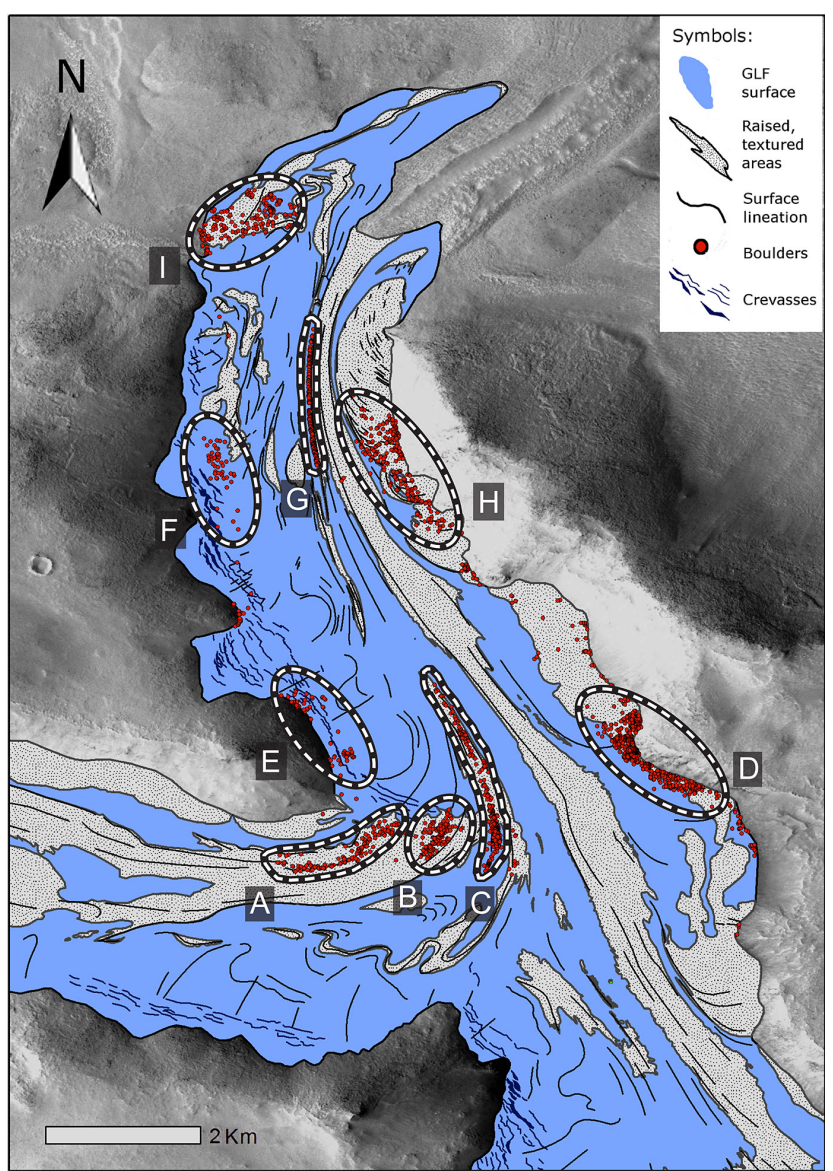

Figure 9. Geomorphological map and interpretation of boulder clusters A-I located on the surface of GLF \#498, illustrated in Fig. 8 .

from further up-GLF. Inspection of Fig. 8c indicates that the closest likely source areas for these trains are from along the steep northern margin of the GLF's trunk for populations A and B (marked "II." in Fig. 8c) and as a medial moraine extending from a promontory separating the GLF trunk from a tributary flowing into it from the south for population $\mathrm{C}$ (marked "I." in Fig. 8c). Both of these likely source areas are at least $8 \mathrm{~km}$ up-flow of their corresponding supra-GLF boulder populations. In this case, and assuming that populations $\mathrm{C}$ and $\mathrm{G}$ are part of the same feature, then the boulders at the far end of population $\mathrm{G}$ appear to have been transported at least $15 \mathrm{~km}(8 \mathrm{~km}$ from the head of the tributary flow unit to population $\mathrm{C}$ and a further $7 \mathrm{~km}$ to the distal end of population G). In the absence of any firm age constraint on this particular GLF, we adopt a "best-estimate" age for its formation of $2 \mathrm{Ma}$, at the onset of the proposed "Late Amazonian" ice age, and a likely age range from $5 \mathrm{Ma}$, the middle of the last major ice age on Mars, to $0.5 \mathrm{Ma}$, the end of the proposed Late Amazonian ice age (Sect. 1.1.3 above). Thus, if boulder transport was initiated at the time of GLF formation from point "I." in Fig. 8c it follows that, for those boulders to have been transported passively to the distal end of population G, GLF \#498's minimum centreline velocity was within the range of $3-30 \mathrm{~mm} \mathrm{a}^{-1}$, with a best-estimate value of $7.5 \mathrm{~mm} \mathrm{a}^{-1}$ averaged over $2 \mathrm{Ma}$.

Finally, the nature of boulder train elongation on the surface of GLF \#498 is consistent with more rapid motion along the approximate centerline of the GLF (populations A, B, C and $\mathrm{G}$, which are highly elongate) than at its margins (populations D, E, F, H and I, which are less elongate), providing independent support for the normal, plan-form flow pattern reconstructed from crevasse patterns on other GLFs (Sect. 2.3 above).

\section{GLF hydrology}

\subsection{Present-day GLF hydrology}

Although still debated (see Ehlmann, 2014; Haberle, 2014), early Mars appears to have been both warmer and wetter than at present (Kargel, 2004). Current surface conditions are relatively cold and dry (see Sect. 1 above), and are consequently no longer conductive to the survival of surface water. Nonetheless, seasonal variations in temperature are sufficient to induce occasional melting as evidenced, for example, by the intermittent discoloration of surface slope deposits in the southern mid-latitudes, inferred by McEwen et al. (2011) to indicate the effects of occasional near-surface moisture. Further, the presence of gullies incised into unconsolidated sediments has been interpreted as the result of intermittent fluvial erosion (Dickson and Head, 2009; Balme et al., 2006, 2013; Soare et al., 2014), as were similar gullies incised into pro-GLF headwall materials on the well-studied GLF \#948 located in Crater Greg, eastern Hellas (Hubbard et al., 2011).

\section{Case study: supra-GLF channel networks}

Despite evidence, summarized above, pointing to the intermittent melting of near-surface ice in Mars' mid- and low latitudes, such melting has, to our knowledge, in only one case been associated with GLFs. Hubbard et al. (2011) reported the presence of numerous incisions, typically $\sim 1 \mathrm{~m}$ wide and tens of metres long, linking the edges of frost or contraction polygons (their "polygonized terrain") on the surface of GLF \#948 (their Fig. 9). These were preferentially aligned subparallel to the $\sim 10^{\circ}$ local slope and they were interpreted as gullies formed by fluvial erosion resulting from the occasional melting of ice located immediately below the GLF's unconsolidated dust mantle. This interpretation, however, was proposed only tentatively because the incised segments were short and did not link up to form a coherent network, and also because liquid water is not stable on Mars' cold, dry and low-pressure surface. Here, we extend this analysis to other GLFs to evaluate the nature and degree of recurrence of this landform in other, similar settings. 

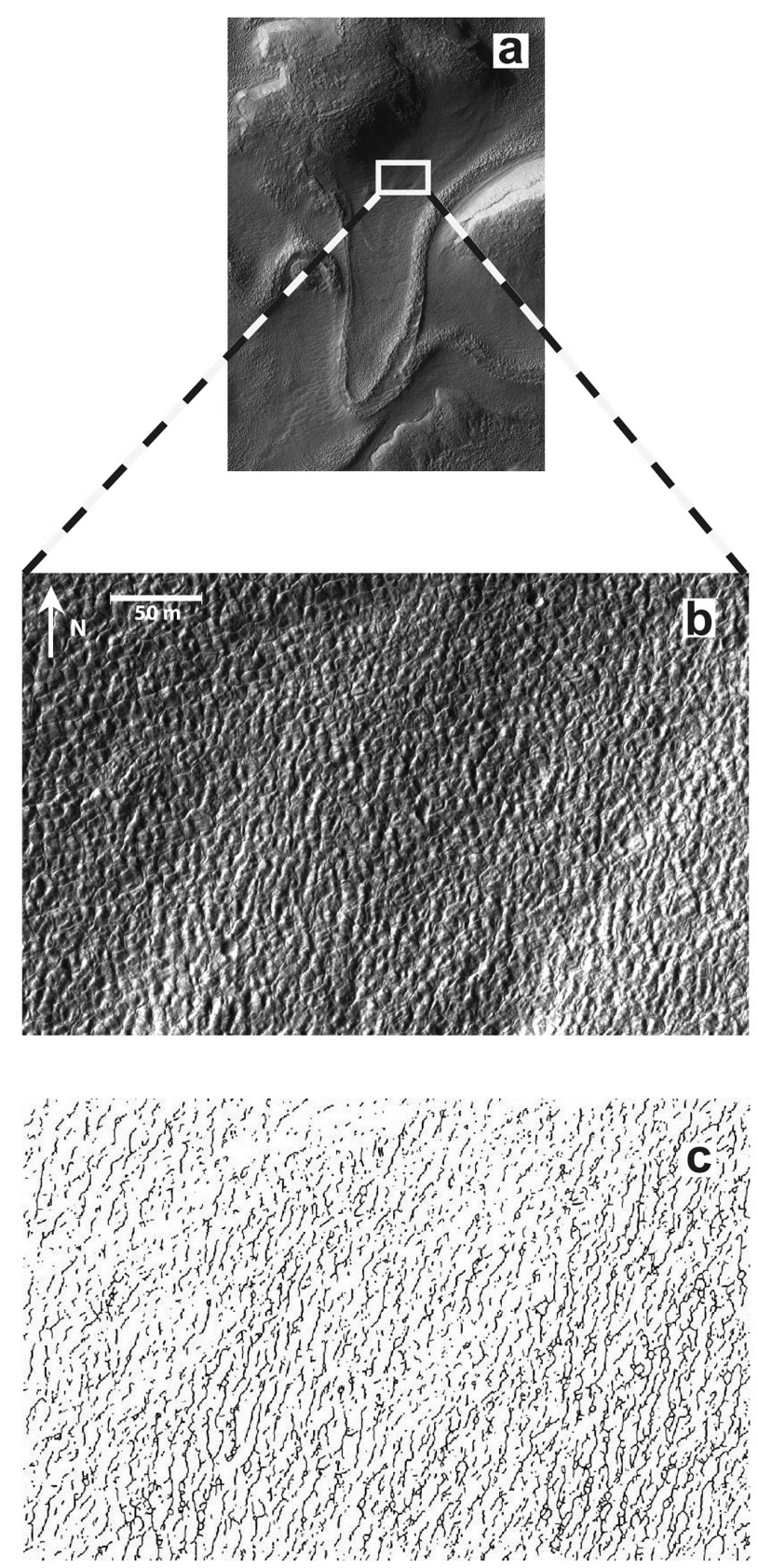

Figure 10. Surface incisions on GLF \#947 imaged by HiRISE to supplement those reported on GLF \#948 by Hubbard et al. (2011). GLF \#947 (a) with an expansion of the incised terrain (b) and trace of incised segments (c).

Because of the small scale of the polygons and incisions involved, target GLFs were restricted to those with highresolution HiRISE coverage, revealing at least six with extensive areas of surface incision. While four of these are located within or near to Hellas Planitia's Crater Greg (GLF \# 930, 947, 948 and 951) the other two are located on the dichotomy boundary in Protonilus Mensae (GLFs \#1310 ${ }^{1}$ and \#390). Examination of these incised supra-GLF zones, one of which is presented for illustration in Fig. 10, reveals similar dimensions and slope-parallel orientation to those observed on GLF \#948. Individual incised segments are also, in all cases, limited in length to a maximum of some tens of metres, while none of the cases identified develops a coherent tributary-based drainage network (e.g., Fig. 10). These similarities strongly indicate that all such incised terrains have been formed and subsequently influenced by a similar process set, operating widely in Mars' mid-latitudes. These characteristics are consistent with the formation of incisions by occasional surface melting, perhaps beneath a thin layer of surface dust, enhancing albedo and local energy transfer (e.g., Nicholson and Benn, 2006), on the relatively steep edges of surface periglacial patterned ground (Gallagher et al., 2011). The short reach length and absence of a coherent channel network is also consistent with the short-lived nature of any such liquid water, evaporating before sufficient discharge can develop to form a supra-GLF drainage network.

\subsection{Former GLF hydrology}

With the notable exception of the proposed intermittent small-scale surface melting proposed above (Sect. 3.1.), present-day GLFs show little or no sign of the presence or influence of liquid water. For example, no evidence of proGLF fluvial activity has been reported, and flow is almost certainly achieved solely through ice deformation, whether ductile or brittle (Sect. 2.3, above). Current martian GLFs therefore appear to be cold throughout. However, this may not have always been the case, even up to the recent geological past. Indeed, the recently expanded extent and thickness of GLFs during the LMGM (Sect. 2.2. above) makes insulation of the bed beneath thick ice more likely than at present. Although former ice thicknesses are not known, precluding thermal modeling, large-scale regional glaciation has been proposed (Kargel and Strom, 1992; Kargel et al., 1995; Fastook et al., 2014) and several landforms have been interpreted as indicative of, or consistent with, former wet-based glaciation. These include, for example, MLRs, the formation of which was proposed by Arfstrom and Hartmann (2005) possibly to involve subglacial squeezing. At the larger scale (and longer time span), sinuous and anastomosing ridge networks, elongate bedforms and large-scale grooves located in southern Argyre Planitia $\left(\sim 30-55^{\circ} \mathrm{S}\right)$ were interpreted by Banks and Pelletier (2008) and Banks et al. (2009) as subglacial eskers, mega-scale glacial lineations (MSGL) and glacial erosional grooving, respectively. The formation of these features would have required the area to have been covered by a large, wet-based ice mass (e.g., Bernhardt et al.,

\footnotetext{
${ }^{1}$ This particular GLF is visible in HiRISE image ESP_019213_2210, which was acquired after the inventory of Souness et al. (2012). We therefore give it the next-available designation of \#1310.
} 
2013). To form MSGL, this ice mass would also have to have been, for some period of time, sliding rapidly over its substrate, almost certainly lubricated by subglacial water (e.g., Clark, 1994). Although these features are undated, Banks et al. $(2008,2009)$ considered them to have been formed in preAmazonian times.

More recently, Hubbard et al. (2011) interpreted the basin of GLF \#948 in terms of an upper zone occupied by a remnant dust-mantled ice mass, and a lower zone now exhibiting relict bedforms. These bedforms were classified as "mound and tail" terrain and "linear" terrain and were likened to terrestrial drumlins and MSGL, respectively. Since both of these landforms are predominantly associated with wet-based glacial conditions on Earth, these authors proposed that such conditions may have prevailed beneath GLF \#948 at a time in the past when it had expanded and thickened to fill its moraine-bounded basin. This interpretation, however, was considered side by side with an alternative - not involving wet-based glaciation - based on the mound and tail and linear terrains representing degraded supra-GLF forms, in this case wind-blown dune deposits and exposed longitudinal foliation, respectively. Finally, Hubbard et al. (2011) also reported the presence of "rectilinear ridge" terrain located outside the current GLF basin, as enclosed by the welldefined MLRs. This terrain was likened to moraine-mound complexes on Earth, the formation of which again suggests either the direct presence of water, if formed as outwash deposits (Lukas, 2005) or crevasse fills (Sharp, 1985), or the existence or polythermal glaciation if formed by glacial thrusting (Hambrey et al., 2005). However, the possibility of coldbased formation, in this case as proglacial thrust blocks, was not entirely discounted.

\section{Summary}

With the aid of high-resolution imagery, particularly from the CTX and HiRISE cameras, several major advances have been made in a short period of time concerning Mars' mid-latitude GLFs. Thus, the following points are now known with some certainty:

- Many GLFs were previously more extensive and thicker than at present, possibly now representing the remnants of former large ice sheets. In Sect. 2.2 (above) we identify a distinctive proglacial zone some $3 \mathrm{~km}$ wide surrounding a GLF located in Phlegra Montes. This zone, bounded along its distal edge by MLRs is interpreted as having been recently deglaciated and is likened to a similar proglacial region bounding Midre Lovénbreen, Svalbard, on Earth.

- GLFs flow slowly downslope through a combination of ductile and (less common) brittle deformation. In Sect. 2.3.3 (above) we identify and interpret four contrasting sets of crevasses located on two martian GLFs in terms of variable strain regimes. These crevasses are also shown to range from being relatively fresh in appearance, implying a correspondingly young age, to appearing blunt and degraded, implying earlier formation and possibly a relict current condition.

- GLFs have the ability to transport debris, forming large bounding moraines and depositing boulder trains extending for several kilometers along-GLF. In Sect. 2.4 (above) we identify an extensive supra-GLF debris train which we interpret in terms of passive transport from specific ice-marginal supply points. Reconstructing boulder transport distances since GLF formation (over the range 5.0 to $0.5 \mathrm{Ma}$, with a best-estimate age of $2.0 \mathrm{Ma} \mathrm{BP}$ ) yields an equivalent provisional GLF surface velocity range of $3-30 \mathrm{~mm} \mathrm{a}^{-1}$, with a best estimate of $\sim 7.5 \mathrm{~mm} \mathrm{a}^{-1}$.

- GLFs currently show little influence of liquid water, confined to postulated intermittent surface melting which is insufficient to form coherent supra-GLF drainage. In Sect. 3.1 (above) we illustrate that such supra-GLF incised channels occur on several GLFs and are not confined to the single instance at which they have hitherto been reported. However, more extensive former GLFs, and/or their predecessor ice masses, may have been partially wet-based.

Despite this information, many of the most fundamental glaciological aspects of GLFs remain unknown. These include the following:

- It is not known whether GLFs are currently active or whether they are decaying relics of previously active forms. Diagnostic indicators of such activity would include any indication of motion (addressed below) and a surface profile that is in balance with current climatic conditions, as indicated by a spatially-distributed numerical model of GLF flow.

- The previous extent of GLFs, and their putative parent ice sheets, is still only poorly understood. This requirement could be addressed through additional field mapping at a variety of spatial scales, based on CTX or High Resolution Stereo Camera (HRSC) images at the regional scale to HiRISE images at a local scale. Such mapping could be targeted at identifying markers of former ice extent such as specific surface terrains, subglacial deposits and ice-marginal moraines.

- The thermal regime of former GLFs is unknown, and the possibility of partial wet-based conditions remains unproven and their extent unevaluated. These issues could be evaluated empirically or theoretically, ideally through a combination of both. Empirical evidence might include the identification of indicators diagnostic 
of wet-based conditions (e.g., bedforms such as megascale glacial lineations) or of subglacial drainage (e.g., meltwater channels or eskers). Theoretically, former thermal regime could be estimated from the application of a thermomechanically coupled ice-flow model to reconstructed former ice mass geometries under realistic climatic conditions for the time.

- The basic mass-balance regime of GLFs is unknown. Whatever the spatial expression of this regime, there is no compelling climatological reason for it to comply with the common terrestrial valley-glacier model of net accumulation at high elevations gradually giving way to net ablation at low elevations. This is possibly the most challenging unknown GLF property to elucidate, and would likely require several lines of evidence to be combined. Central to these might be a regional evaluation of GLF extent in the light of corresponding variations in meteorological conditions. A modeling approach may also help elucidate the mass-balance regime of GLFs, for example through comparing modeled GLF geometries and flow with empirical data under a variety of modeled mass-balance patterns.

- The 3-D geometry and internal structure of GLFs is unknown. Although SHARAD radar data are available and capable of mapping ice thickness, the data are of fairly coarse resolution and have limited spatial coverage. Very little information is therefore available to allow the basal interface of GLFs to be identified and mapped. This property is also critically important because spatially distributed models of ice mass flow depend sensitively on accurate bed geometry. In this case, new and existing SHARAD data could usefully be mined to locate intersections with known GLFs, providing a first approximation of bed profiles. Further to that, modeling-based sensitivity analyses (to GLF depth) could also be used to constrain likely bed geometries.

- Mechanisms of GLF motion are poorly known, and, apart from the estimate of $3-30 \mathrm{~mm} \mathrm{a}^{-1}$ presented herein (Sect. 2.4 above), it has not yet been possible to measure surface velocities on any Martian GLF. Further research based on indicators of surface displacement such as the boulder analysis presented herein - could usefully be used to refine the range we propose. As the period of time between repeat HiRISE images of certain GLFs increases, it may also become possible to identify contemporary GLF motion on the basis of feature or speckle tracking. Indeed, a single such measurement would provide a major advance in our understanding of the dynamic glaciology of martian GLFs, particularly if the GLF concerned could also be modeled.

- GLF-related landforms such as lineations, drumlinlike forms, surface cracks/gullies and possible eskers remain largely unexplored and their basic morphometric characteristics are unreported. Targeted mapping from HiRISE images remains the best way to identify and evaluate such landforms. The online inventory accompanying Souness et al. (2012) would provide a suitable starting point for identifying candidate regions of interest.

- Although considered to be rich in water ice, the internal composition of GLFs remains unknown, despite these material properties having important implications for GLF dynamics and our ability to model GLF behaviour accurately. Apart from direct sampling in the future, which is unlikely in the near term, SHARAD data analysis may be combined with numerical modeling to further constrain the internal composition of GLFs. Opportunistic images, for example shortly following a meteorite impact, may also continue to yield information relevant to GLF subsurface conditions.

These issues deserve research attention to improve our understanding of the surface features of Mars and, due to glaciers being effective recorders of climate change, the planet's past environmental conditions. It is also worth noting that the well-insulated base of thick ice masses represents one of the most likely geologically recent environments on Mars for the existence of the wet and relatively warm conditions that are conducive to life.

Acknowledgements. We acknowledge the HiRISE team, University of Arizona, and NASA/JPL for making the HiRISE images we investigate herein available to the public. We thank Ajay Limaye for preparing the 3-D image presented in Fig. 1. We also thank Matthew Balme, Wilfried Haeberli, Michael Kuhn and Sara Springman for reviewing or commenting on an earlier version of the manuscript, and Martin Schneebeli for editing.

Edited by: M. Schneebeli

\section{References}

Arfstrom, J. and Hartmann, W. K.: Martian flow features, morainelike ridges, and gullies: Terrestrial analogs and interrelationships, Icarus, 174, 321-335, 2005.

Baker, D. M. H., Head, J. W., and Marchant, D. R.: Flow patterns of lobate debris aprons and lineated valley fill north of Ismeniae Fossae, Mars: Evidence for extensive mid-latitude glaciation in the Late Amazonian, Icarus, 207, 186-209, 2010.

Balme, M., Mangold, N., Baratoux, D., Costard, F., Gosselin, M., Masson, P., Pinet, P. and Neukum, G.: Orientation and distribution of recent gullies in the southern hemisphere of mars: Observations from High Resolution Stereo Camera/Mars Express (HRSC/MEX) and Mars Orbiter Camera/Mars Global Surveyor (MOC/MGS) data, J. Geophys. Res.-Planets, 111, E05001, doi:10.1029/2005JE002607, 2006. 
Balme, M. R., Gallagher, C. J., and Hauber, E.: Morphological evidence for geologically young thaw of ice on Mars: A review of recent studies using high-resolution imaging data, Prog. Phys. Geogr., 37, 289-324, 2013.

Banks, M. E. and Pelletier, J. D.: Forward modeling of ice topography on Mars to infer basal shear stress conditions, J. Geophys. Res.-Planets, 113, E01001, doi:10.1029/2007JE002895, 2008.

Banks, M. E., Lang, N. P., Kargel, J. S., McEwen, A. S., Baker, V. R., Grant, J. A., Pelletier, J. D., and Strom, R. G.: An analysis of sinuous ridges in the southern Argyre Planitia, Mars using HiRISE and CTX images and MOLA data, J. Geophys. Res.Planets, 114, E09003, doi:10.1029/2008JE003244, 2009.

Bernhardt, H., Hiesinger, H., Reiss, D., Ivanov, M., and Erkeling, G.: Putative eskers and new insights into glacio-fluvial depositional settings in southern Argyre Planitia, Mars, Planet. Space Sci., 85, 261-278, 2013.

Byrne, S., Russel, P., Pathare, A., Becerra, P., Molaro, J., Mattson, S., and Mellon, M. T.: Fracturing the icy polar cliffs of Mars. 44th Lunar and planetary Science Conference, The Woodlands, Texas, 1659, 18-22 March, 2013.

Clark, C. D.: Large-scale ice-moulding: a discussion of genesis and glaciological significance, Sediment. Geol., 91, 253-268, 1994.

Colaprete, A. and Jakosky, B. M.: Ice flow and rock glaciers on Mars, J. Geophys. Res.-Planets, 103, 5897-5909, 1998.

Dickson, J. L. and Head, J. W.: The formation and evolution of youthful gullies on Mars: Gullies as the late-stage phase of Mars' most recent ice age, Icarus, 204, 63-86, 2009.

Dickson, J. L., Head, J. W., and Marchant, D. R.: Late Amazonian glaciation at the dichotomy boundary on Mars: Evidence for glacial thickness maxima and multiple glacial phases, Geology, 36, 411-414, 2008.

Dickson, J. L., Head, J. W., and Marchant, D. R.: Kilometer-thick ice accumulation and glaciation in the northern mid-latitudes of Mars: Evidence for crater-filling events in the Late Amazonian at the Phlegra Montes, Earth Planet. Sci. Lett., 294, 332-342, 2010.

Dundas, C. M. and Byrne, S.: Modeling sublimation of ice exposed by new impacts in the martian mid-latitudes, Icarus, 206, 716728,2010

Ehlmann, B. L.: The First Billion Years - Warm and Wet vs. Cold and Icy?, Eighth International Conference on Mars, Pasadena, California, 1245, 14-18 March., 2014.

Fastook, J. L., Head, J. W., and Marchant, D. R.: Formation of lobate debris aprons on Mars: Assessment of regional ice sheet collapse and debris-cover armoring, Icarus, 228, 54-63, 2014.

Forget, F., Haberle, R. M., Montmessin, F., Levrard, B., and Head, J. W.: Formation of glaciers on Mars by atmospheric precipitation at high obliquity, Science, 311, 368-371, 2006.

Gallagher, C., Balme, M. R., Conway, S. J. and Grindrod, P. M.: Sorted clastic stripes, lobes and associated gullies in highlatitude craters on Mars: Landforms indicative of very recent, polycyclic ground-ice thaw and liquid flows, Icarus, 211, 458471, 2011

Garvin, J. B., Head, J. W., Marchant, D. R., and Kreslavsky, M. A.: High-latitude cold-based glacial deposits on Mars: Multiple superposed drop moraines in a crater interior at 70 degrees $\mathrm{N}$ latitude, Meteorit. Planet. Sci., 41, 1659-1674, 2006.

Goldsby, D. L. and Kohlstedt, D. L.: Superplastic deformation of ice: Experimental observations, J. Geophys. Res., 106, 1101711030, 2001.
Haberle, R. M.: Mars: The First Billion Years - Warm and Wet vs. Cold and Icy?, Eighth International Conference on Mars, Pasadena, California, 1270, 14-18 March, 2014.

Hambrey, M. J., Murray, T., Glasser, N. F., Hubbard, A., Hubbard, B., Stuart, G., Hansen, S. and Kohler, J.: Structure and changing dynamics of a polythermal valley glacier on a centennial timescale: Midre Lovenbreen, Svalbard, J. Geophys. Res.-Earth Surf., 110, F01006, doi:10.1029/2004JF000128, 2005.

Harbor, J. M.: Development of glacial-valley cross sections under conditions of spatially variable resistance to erosion, Geomorphology, 14, 99-107, 1995.

Hartmann, W. K., Thorsteinsson, T., and Sigurdsson, F.: Martian hillside gullies and Icelandic analogs, Icarus, 162, 259-277, 2003.

Hartmann, W. K., Ansan, V., Berman, D. C., Mangold, N., and Forget, F.: Comprehensive analysis of glaciated martian crater Greg, Icarus, 228, 96-120, 2014

Head, J. W. and Marchant, D. R.: Cold-based mountain glaciers on Mars: Western Arsia Mons. Geology, 31, 641-644, 2003.

Head, J. W., Mustard, J. F., Kreslavsky, M. A., Milliken, R. E., and Marchant, D. R.: Recent ice ages on Mars, Nature, 426, 797-802, 2003.

Head, J. W., Neukum, G., Jaumann, R., Hiesinger, H., Hauber, E., Carr, M., Masson, P., Foing, B., Hoffmann, H., Kreslavsky, M., Werner, S., Milkovich, S., van Gasselt, S., and the HRSC CoInvestigator Team: Tropical to mid-latitude snow and ice accumulation, flow and glaciations on Mars, Nature, 434, 346-351, 2005.

Head, J. W., Marchant, D. R., Dickson, J. L., Kress, A. M., and Baker, D. M.: Northern mid-latitude glaciation in the Late Amazonian period of Mars: Criteria for the recognition of debriscovered glacier and valley glacier landsystem deposits, Earth Planet. Sci. Lett., 294, 306-320, 2010.

Herzfeld, U. C. and Clarke, G. K. C.: Analysis of crevasse patterns as indicators of ice dynamics using structural glaciology and geostatistical classification, American Geophysical union, Fall Meeting, San Francisco, IP21A-0674, 10-14 December 2001.

Hobley, D. E. J., Howard, A. D., and Moore, J. M.: Fresh shallow valleys in the Martian midlatitudes as features formed by meltwater flow beneath ice, J. Geophys. Res. Planets, 119, E04396, doi:10.1002/2013JE004396, 2014.

Holt, J. W., Safaeinili, A., Plaut, J. J., Head, J. W., Phillips, R. J., Seu, R., Kempf, S. D., Choudhary, P., Young, D. A., Putzig, N. E., Biccari, D., and Gim, Y.: Radar sounding evidence for buried glaciers in the southern mid-latitudes of Mars, Science, 322, 1235-1238, 2008.

Hubbard, B., Milliken, R. E., Kargel, J. S., Limaye,, A., and Souness, C.: Geomorphological characterisation and interpretation of a mid-latitude glacier-like form: Hellas Planitia, Mars, Icarus, 211, 330-346, 2011.

Hudson, T. L., Aharonson, O., and Schorghofer, N.: Laboratory experiments and models of diffusive emplacement of ground ice on Mars, J. Geophys. Res. Planets, 114, E01002, doi:10.1029/2008JE003149, 2009.

Kargel, J. S.: Mars: a warmer, wetter planet, London, Springer, 2004.

Kargel, J. S. and Strom, R. G.: Ancient glaciation on Mars, Geology, 20, 3-7, 1992. 
Kargel, J. S., Baker, V. R., Beget, J. E., Lockwood, J. F., Pewe, T. L., Shaw, J. S., and Strom, R. G.: Evidence of ancient continentalglaciation in the martian northern plains, J. Geophys. Res. Planets, 100, 5351-5368, 1995.

Laskar, J., Correia, A. C. M., Gastineau, M., Joutel, F., Levrard, B., and Robutel, P.: Long term evolution and chaotic diffusion of the insolation quantities of Mars, Icarus, 170, 343-364, doi:10.1013/j.icarus.2004.04.005, 2004.

Levy, J. S., Head, J. W., and Marchant, D. R.: Lineated valley fill and lobate debris apron stratigraphy in Nilosyrtis Mensae, Mars: Evidence for phases of glacial modification of the dichotomy boundary, J. Geophys. Res. Planets, 112, E08004, doi:10.1029/2006JE002852, 2007.

Li, H., Robinson, M. S., and Jurdy, D. M.: Origin of martian northern hemisphere mid-latitude lobate debris aprons, Icarus, 176, 382-394, doi:10.1016/j.icarus.2005.02.011, 2005.

Lukas, S.: A test of the englacial thrusting hypothesis of "hummocky" moraine formation: case studies from the northwest Highlands, Scotland, Boreas, 34, 287-307, 2005.

Mair, R. and Kuhn, M.: Temperature and movement measurements at a bergschrund, J. Glaciol., 40, 561-565, 1994.

Mangold, N.: Geomorphic analysis of lobate debris aprons on Mars at Mars Orbiter Camera scale: Evidence for ice sublimation initiated by fractures, J. Geophys. Res., 108, E048021, doi:10.1029/2002JE001885, 2003.

Marchant, D. R. and Head, J. W.: Tongue-shaped lobes on Mars: morphology, nomenclature and relation to rock glacier deposits, Sixth International Conference on Mars, 3091, 20-25 July, 2003.

McEwen, A. S., Dundas, C. M., Mattson, S. S., Toigo, A. D., Ojha, L., Wray, J. J., Chojnacki, M., Byrne, S., Murchie, S. L., Thomas, N.: Recurring slope lineae in equatorial regions of Mars, Nat. Geosci., 7, 53-58, 2011

Milliken, R. E., Mustard, J. F., and Goldsby, D. L.: Viscous flow features on the surface of Mars: Observations from high-resolution Mars Orbiter Camera (MOC) images, J. Geophys. Res., Planets, 108, E065057, doi:10.1029/2002JE002005, 2003.

Nicholson, L. and Benn, D. I.: Calculating ice melt beneath a debris layer using meteorological data, J. Glaciol., 52, 463-470, 2006.

Phillips, R. J., Zuber, M. T., Smrekar, S. E., Mellon, M. T., Head, J. W., Tanaka, K. L., Putzig, N. E., Milkovich, S. M., Campbell, B. A., Plaut, J. J., Safaeinili, A., Seu, R., Biccari, D., Carter, L. M., Picardi, G., Orosei, R., Mohit, P. S., Heggy, E., Zurek, R. W., Egan, A. F., Giacomoni, E., Russo, F., Cutigni, M., Pettinelli, E., Holt, J. W., Leuschen, C. J., and Marinangeli, L.: Mars north polar deposits: Stratigraphy, age, and geodynamical response, Science, 320, 1182-1185, 2008.

Pierce, T. L. and Crown, D. A.: Morphologic and topographic analyses of debris aprons in the eastern Hellas region, Mars, Icarus, 163, 46-65, 2003.

Plaut, J. J., Safaeinili, A., Holt, J. W., Phillips, R. J., Head, J. W., Seu, R., Putzig, N. E., and Frigeri, A.: Radar evidence for ice in lobate debris aprons in the mid-northern latitudes of Mars, Geophys. Res. Lett., 36, L02203, doi:10.1029/2008GL036379, 2009.

Read, P. L. and Lewis, S. R.: The Martian Climate Revised: Atmosphere and Environment of a Desert Planet, Praxis Publishing, Chichester, 2004.
Russell, P., Thomas, N., Byrne, S., Herkenhoff, K., Fishbaugh, K., Bridges, N., Okubo, C., Milazzo, M., Daubar, I., Hansen, C., and McEwen, A.: Seasonally active frost-dust avalanches on a north polar scarp of Mars captured by HiRISE, Geophys. Res. Lett., 35, L23204, doi:10.1029/2008GL035790, 2008.

Sato, H., Kurita, K., and Baratoux, D.: The formation of floorfractured craters in Xanthe Terra, Icarus, 207, 248-264, 2010.

Schon, S. C., Head, J. W., and Milliken, R. E.: A recent ice age on Mars: Evidence for climate oscillations from regional layering in mid-latitude mantling deposits, Geophys. Res. Lett., 36, L15202, doi:10.1029/2009GL038554, 2009.

Seu, R., Phillips, R. J., Alberti, G., Biccari, D., Bonaventura, F., Bortone, M., Calabrese, D., Campbell, B. A., Cartacci, M., Carter, L. M., Catallo, C., Croce, A., Croci, R., Cutigni, M., Di Placido, A., Dinardo, S., Federico, C., Flamini, E., Fois, F., Frigeri, A., Fuga, O., Giacomoni, E., Gim, Y., Guelfi, M., Holt, J. W., Kofman, W., Leuschen, C. J., Marinangeli, L., Marras, P., Masdea, A., Mattei, S., Mecozzi, R., Milkovich, S. M., Morlupi, A., Mouginot, J., Orosei, R., Papa, C., Paterno, T., Persi del Marmo, P., Pettinelli, E., Pica, G., Picardi, G., Plaut, J. J., Provenziani, M., Putzig, N. E., Russo, F., Safaeinili, A., Salzillo, G., Santovito, M. R., Smrekar, S. E., Tattarletti, B., and Vicari, D.: Accumulation and erosion of Mars' south polar layered deposits, Science, 317, 1715-1718, 2007.

Sharp, M.: "Crevasse-fill" ridges - a landform type characteristic of surging glaciers?, Geograf. Annal., 67A, 213-220, 1985.

Sharp, R. P.: Mars: Fretted and chaotic terrains, J. Geophys. Res., 78, 4073-4083, 1973.

Sinha, R .K. and Murty, S. V. S.: Evidence of extensive glaciation in Deuteronilus Mensae, Mars: Inferences towards multiple glacial events in the past epochs, Planet. Space Sci., 86, 10-32, 2013.

Soare, R. J., Conway, S. J., and Dohm, J. M.: Possible ice-wedge polygons and recent landscape modification by "wet" periglacial processes in and around the Argyre impact basin, Mars, Icarus, 233, 214-228, 2014.

Souness, C. and Hubbard, B.: Mid-latitude glaciation on Mars, Progr. Phys. Geogr., 36, 238-261, 2012.

Souness, C. J. and Hubbard, B.: An alternative interpretation of late Amazonian ice flow: Protonilus Mensae, Mars, Icarus, 225, 495 505, 2013.

Souness, C., Hubbard, B., Milliken, R. E., and Quincey, D.: An inventory and population-scale analysis of martian glacier-like forms, Icarus, 217, 243-255, 2012.

Squyres, S. W.: Martian fretted terrain: Flow of erosional debris, Icarus, 34, 600-613, 1978.

Squyres, S. W.: The distribution of lobate debris aprons and similar flows on Mars, J. Geophys. Res. Solid Earth, 84, 8087-8096, 1979.

Touma, J. and Wisdom, J.: The Chaotic Obliquity of Mars, Science, 259, 1294-1297, 1993.

Vaughan, D. G.: Relating the occurrence of crevasses to surface strain rates, J. Glaciol., 39, 255-266, 1993. 